\title{
is Research Square \\ Concept analysis of loneliness in older adults: A hybrid model
}

Razieh Bandari

Semnan university medical of sciences

Farahnaz Mohammadi Shahboulaghi ( $\nabla$ farahnazmohammadi84@gmail.com )

USWR

Hamid Reza Khankeh

UWSR

Abbas Ebadi

BUMS

Ali Montazeri

Iranian Institute for Health Sciences Research

Research article

Keywords: Loneliness, Older adults, Concept Analysis, Hybrid Approach

Posted Date: May 7th, 2020

DOI: https://doi.org/10.21203/rs.3.rs-26446/v1

License: (c) (i) This work is licensed under a Creative Commons Attribution 4.0 International License.

Read Full License 


\section{Abstract}

Background: Loneliness is an ontological structure in human existence that can occur in all stages of life. The purpose of this qualitative study was to clarify the meaning and the nature of Ioneliness in Iranian older adults.

Methods: Loneliness in older adults was examined in three phases: (1) the theoretical phase; (2) the fieldwork and (3) the analytical phase. The hybrid concept analysis method was performed to explore the data and synthesis the findings on three key issues including attributes, antecedents, and consequences. Finally, a working definition was synthesized.

Results: The critical attributes of loneliness included a variety of topics including suffering, and feeling of worthlessness. Antecedents included distal and proximal factors. The consequences of loneliness in most instances were negative and disturbing. The final definition originated from the theoretical phase and fieldwork was as follows: 'loneliness is an unpleasant, negative, annoying, hard, scary and painful personal experience that causes feeling of despair, uselessness, hopelessness, depression, anxiety and seeing the world in black'.

Conclusion: The findings from this study introduce a new definition for loneliness that includes a combination of attributes, antecedents and consequences for the concept.

\section{Background}

Medical advances in the second half of the twentieth century have led to a relative increase in human life expectancy [1]. As such the number of elderly people is increasing in all societies worldwide [2]. Aging is a biological process that encompasses all living aspects including physiological and psychological changes along with different social actions and reactions [3].

The well-being of older people in general and their loneliness in particular have been important topics in recent arguments among scholars from different disciplines[4]. For instance a report by World Health Organization pointed out that although elderly enjoy from a relative decent life, they suffer from loneliness to a great extend [5]. Thus it is argued that it is essential to deal with loneliness among elderly as part of policies to achieve a "successful" aging [6].

In general loneliness is a phenomenon that can occur in all age groups [7] and its determinants could vary by age group and stage of life [8]. Research on younger age groups has shown that personality traits are of primary importance [9] while for the older adults conditions such as having a partner and health status are the most prominent determinants of loneliness [10]. However, in examining the determinants of loneliness, we should specifically focus on older adults because younger people have a higher chance to manage loneliness for several reasons including usually living with family, good health status and more social activity and integration [11]. Therefore, an understanding of the concept of loneliness in older adults merits serious attention. 
The process of concept analysis leads to clarifying a concept by studying the main elements of the concept and determining its nature and function. In addition, because concepts are the foundation of theories, their clarification results in the expansion of knowledge, reaching a common perception of phenomena, and preventing conflicts and personal impressions [12]. This study aimed to perform a concept analysis of older adult's loneliness using his hybrid method. The method is one of the appropriate approaches to the analysis of concepts in clinical practice. As recommended using this method might help to define the phenomenon or concept under study and to evaluate it comprehensively [13].

\section{Methods}

\section{Design}

A hybrid model was used to analyze the concept of loneliness in older adults. The model provides a method for conceptualizing and clarifying a concept as well as developing theories. The hybrid model is used to clarify abstract and vague concepts in nursing. This model consists of three phases: theoretical analysis, field work, and final analysis [14].

\section{The theoretical phase}

In the first phase (i.e., theoretical analysis), a review of literatures was conducted. The search engines included PubMed, CINAHL, Scopus, Web of Science, EMBASE, and AgeLine using the keywords 'concept', 'Ioneliness', 'homesickness', 'old', 'old', 'eld*', 'geriatric*', 'aging', 'age*', 'later life', 'senior', 'nonagenarian', 'octogenarian', 'centenarian' in the abstract and title of publications. The article abstracts were first reviewed, and only the full text of relevant articles were evaluated. Then, appropriate codes were assigned in order to extract the antecedent, attributes and consequences using qualitative content analysis. In the second phase or fieldwork, the researcher determined the work definition for the field work. In the final analysis, an overall analysis of the data as well as of the results of the two previous phases was conducted, and a comprehensive definition of the concept, according to the background and context of Iran, was presented.

\section{The fieldwork Phase}

After an extensive review of the literature, a fieldwork was followed in order to empirically clarify and explore the concept of loneliness in older adults. Exploring in this phase involved empirical validation of the concept using a qualitative research method with a content analysis approach [12]. The detailed method is described as follows.

\section{Setting and sample}

A purposive sampling method was applied to recruit 14 elderly male and female researcher living in Tehran, Iran. In-depth, semi-structured face-to-face interviews were conducted in a private setting, considering the participants' choices. The inclusion criteria were (a) older adults aged 60 years and over 
(b) residing in an urban area; (c) being able to speak, hear and understand Persian language; and willingness to participate in the study. Eligible participants who provided written consent were interviewed. Maximum variation strategy was used to include a broad spectrum of older adults to assure identifying themes across demographic variations. Demographic characteristics including age, marital status, education, employment status, number of children, living condition, economic status and health status also were recorded. Variations in these characteristics were sought during recruitment.

\section{Data collection}

The main investigator (RB) collected the data. Each interview was begun with a general question about the participant's loneliness experiences. Then the interviewer gradually moved to those aspects more directly related to the research inquiry. Narratives were initiated with the questions: "Do you ever feel that you are alone"? After initial responses, probes and reflective statements were used to follow the participants' thoughts. Interviews lasted for 90 minutes on average. The conversations were audiotaped with the permission of the participants. Data was collected from December 2018 to May 2019. Data Saturation was confirmed when the last three interviews did not add new codes, attributes, or domains. The data collected were immediately transcribed verbatim and analyzed using qualitative content analysis. The method of coding according to qualitative content analysis was used to derive categories and themes from the data, which were identified from the first interviews and then tested and revised through analysis of succeeding interviews. To enhance true value and applicability, the researcher establishes the interview guide that was amended by two pilot interviews before it became the formal instrument of data collection. The transcriptions were also checked with participants frequently for accuracy, and the principal investigator reviewed and discussed the entire interview coding to ensure consistency. To increase interviewer reliability and consistency only one researcher collected, translated, and analyzed the data. For each interview, the outcomes were discussed and members of the research team agreed upon revisions. The principal investigator also carefully reviewed the entire interview coding to confirm consistency.

\section{The final analytic phase}

Findings from the theoretical phase were compared with the fieldwork to produce a refined definition of the loneliness in older adults supported by both the literature and the older adult's perspectives [14]. Permanent, comparative analysis was performed all over the entire data-collection process. As such the research team stepped back from the details of field work and re-examined the data in the light of the preliminary research focus. The final analytic phase was conceptual description through integration of the literature findings and the fieldwork data.

\section{Results}

\section{Review of literature: theoretical phase}

1.1. Definitions in the existing literature 
Overall there were six different definitions of loneliness. Sullivan offered the oldest definition in 1953 and Gierveld introduced the newest definition in 1987. A summary of definitions by different scholars is presented in Table 1.

\subsection{Attributes of loneliness in older adults}

Attributes are 'those characteristics of a concept which appear over and over again' when the concept is defined [15]. Literature review indicated ten key attributes for the concept of loneliness in older adults: 'subjective phenomenon' [16-21], 'lack of meaningful interpersonal relationships' [16, 19-25], 'a wall of sorrow and pain loneliness' [16, 19-21, 26-28], 'struggle for energy and resilience' [16, 19, 24, 29, 30], 'Ioneliness as a time-related experience'[16, 24, 31], 'lack and deprivation' [32-35], 'feeling useless, isolated and unable to keep up with the flow of life'[18, 20-23, 27, 28, 36].

\subsection{Antecedents of loneliness in older adults}

The antecedents of a concept are those events that generally occur before occurrence of the concept [12]. Antecedents of loneliness in older adults that uncovered at theoretical phase included a variety of factors that can be classified into two categories as follows: (a) Distal factors including demographic and sociostructural factors (age, gender, educational level, work, income, health, ethnicity, and migrant status) and personality characteristics (social skills, self-esteem, shyness, anxiety, introversion). (b) Proximal factors including level of social integration, such as the size, the composition and the functioning of the personal network (intimate relationships as well as the broader group of acquaintances, colleagues, neighbors, and extended kin) [37].

\subsection{Consequences of loneliness in older adults}

A range of the consequences of loneliness in older adults was reported. These included morbidity and mortality [38-40], poor physiological health outcomes [4,41], poor psychological health and wellbeing [42, 43], defective immune functioning [44,45], hypertension[46, 47], coronary heart disease (CHD) $[48,49]$, stroke [50, 51], increased risk of physical inactivity and smoking [52], dementia [53, 54], depression[55, 56], low self-esteem, suicide, alcohol and drug abuse[55, 57], sleeping problems[53, 58], disturbed appetite[59, 60], latent causes of hospitalization[41, 61], inflammatory diseases (diabetes, autoimmune disorders like rheumatoid arthritis, lupus) [4, 62], obesity, cancer, poor hearing[63, 64], borderline personality disorder[65, 66], cognitive decline[67,68], Alzheimer's disease $[53,69]$.

\subsection{Working definition derived from theoretical phase}

Loneliness in older adults can be defined as 'an experience of absence of good relationships and unpleasant feelings of lack of intimate attachment and mutual empathy'.

\section{The fieldwork}


Overall nine themes emerged from the data analysis. As such the attributes of loneliness in older adults were 'personal, subjective and individual phenomena', 'sense of suffering', 'breakdown of important interpersonal relationships', 'experience of loneliness at certain times', 'lack of quality and quantity of support resources',' decreasing level of loneliness',' incremental level of loneliness', coping with loneliness', feeling abandoned, worthless'. These are briefly presented as follows.

\subsection{Attributes of loneliness in older adults}

(a): Personal, subjective and individual phenomena

Participants stated that it is not only difficult to describe the loneliness and to express it in words, but also that it is not easy to talk about it since it is often associated with stigma. Sharing one's own loneliness with others was frequently accompanied by shame and embarrassment, as well as a sense of failure.

I think loneliness is largely a subjective phenomenon. I'm sure some people are alone just because of their circumstances, for example because they can't get out of the house. They can't help themselves.I can't understand how some people have no friends; I can't understand that one has no any friends. But I'm sure there are people like this. I think it's a mental attitude that you don't consider yourself old.I don't feel old,In my mind I'm still a 25 or 30 year old,Sometimes I can't believe I'm 67 years old. This seemed a bit impossible, so I think if you think you are old you will grow old.My sister who is younger than me and has not had a happy life,she called me once when she was 60 and said she felt she was an old pensioner. I told her no, you're not 60 years old. You're not old. Your birthday is nearand you don't have to think you're a pensioner, but you must know yourself as someone who has reached a certain age. She looks much older than me,much older than me,others telling me she looks older than you. I think this is partly related to her lifestyle and partly to her attitude about being old. (67-years old woman)

(b) Sense of suffering

Participants described loneliness as highly disturbing emotional condition and are experiencing unpleasant, negative, annoying, difficult, terrifying and painful time. Also, loneliness was introduced as a dark fortune. These themes have appeared in many interviews.

The most painful thing in my life is being alone, you feel that all the sadness in the world is yours,you always think about it,thinking about it makes me crazy,you think no one cares about you,no one is thinking about you,they have forgotten me,lt feels very bad. (78-years old widowed).

Another participant said that:

Loneliness bother me, sometimes I think how miserable I am, how poor I am, why I should have such a fortune. No one can understand this sense of nostalgia. My kids say we are very comfortable since you live with our brother and you are not alone. Yes, I don't live alone I live with my son. But the feeling of being alone is very different from living alone, a feeling that you feel in your heart. Sometimes I sit and 
cry. I ask myself why? Why should I feel so lonely? My leg, my back, all over my body it hurts; but no pain is worse than loneliness. (76-years old widowed).

(c) The breakdown of important interpersonal relationships

Losing a loved one or significant others in life was an important factor for the elderly.

A 70-year-old woman said that:

Loneliness for me is losing loved ones, I lost my mother, lost my husband ... seems part of you going with them.

Another participant said: that:

Absence of a loved one creates a vacuum that no one can fill the void ... (74 years old woman)

An old woman used the word 'tomb' as a symbol for loneliness an said that:

It is like a tomb, the beginning of real loneliness and living alone.

Participants had lost meaningful relationships because of their poor health or weakness or loosing their friends. The elderly lacked emotions, and endorsement of interpersonal relationships. In particular, they wished to receive sympathy from someone of their generation who could understand them. A 69-year-old woman said:

This is probably the worst type of loneliness ... to see your older siblings have died ... and you are getting lonelier every day....

Losing these important relationships would make the elderly find it difficult to accept new relationships. The remaining social network did not always meet their expectations. Without anyone to share his or her world with, life was full of loneliness...

In my opinion, loneliness is a feeling of being empty. The feeling that you have nothing to look for ... you have nothing to wish for. As if you have nothing to live for, you have no future..., as if you have come to an end. (67 year old woman).

Participants noted the process of aging and its associated physical problems, which impeded the continuation of past social activities such as family communication, daily living activities, travel, and sacred pilgrimage. Elderly indicated that diseases such as foot pain, low back pain and motor problems are important barriers to social activity.

My wife died very soon. In early days I used to go to cemetery every day and then twice a week. However, at present I go once every 3 months, or 4 months. Where I go I open my heart, this is the same for going to visit my kids. It was good.Now, from early morning to night I sit at home. I miss my family life so much. It is very difficult. (80-years old man). 
(d) Experience of Ioneliness at certain times

The temporal aspects of loneliness expressed for certain times of the year, seasons or days of the week, evenings, weekends, and holidays.

One can be very lonely, yes, especially in winter. In winter I don't go out very much. I'm afraid of falling. I have never been out of the house on a regular basis, but that has happened to many of my friends. (70years old woman)

(e) Lack of quality and quantity of support resources

Lack of basic requirements for life, lack of special facilities for the elderly, lack of health insurance, lack of family support, lack of access to subsidized food, and adequate transportation services by the participants were cited as a subset of the lack of support resources. The major barriers to accessing services and facilities in the community included lack of awareness of available services, off-road access, and lack of appropriate commuting services.

If there was a law in our country that would protect the elderly,there was proper insurance and accountability, there were living facilitiesolder people should have not been worried about money, living expenses, home, medicine and food.I need to eat meat, milk, yogurt, need fruit just recently, I had an eye surgery. I paid the whole cost. When I was abroad (Netherlands), I was admitted to hospital for stroke and paid nothing. In most instances people can't afford these, these are here (Iran). You have to endure the pain. This is where you realize you are very lonely ... (66-years old widowed).

(f): Decreasing levels of loneliness

For some participants, the experience of loneliness stemmed from a specific traumatic event, often involving the death of a spouse or the onset of a severe and a limiting illness. In this case, the person would often cope with the lack of a spouse or illness or lack of mobility and adjust their daily lives to new conditions. These people gradually feel less loneliness. This path was particularly common in men and women who had been widowed or divorced for years and were able to adapt to new circumstances and develop new friendships:

I became widowed almost two years ago, and it was very difficult for me because I had been caring for my husband for many years. He was blind for many years, so we suffered a lot. But since then ... um ... I've joined to a group of elderly women in the community centers. I only attended one of their meetings and then took a guided tour of Shiraz with them.I went to classes in the evening and started to learn typing because I wanted to update my system. Other than that I've gone to different classes and I'm helping my daughter, a recovering addict,but we don't talk much about it ...l also work a lot in my garden ...I think I'm in a much better position than before and I'm really lucky (69-years old widowed)

(g): Incremental levels of loneliness: 
These levels of loneliness occur throughout most people's lives when they have problems together in mobility, social conditions, health and financial status. Some participants stated that they feel more loneliness at the present time than when they were younger. There was a group of people who said their loneliness was growing but they said loneliness was a gradual process that occurred over a period of time. A number of factors contributed to this process including moving away from friends, deaths of closed friends, changing neighborhoods and living areas, retirement and leaving children, which directly or indirectly led to a decrease in one's social interactions.

Many of our friends have gone abroad, so our group of friends is getting smaller. We have now realized that as you get older you lose your friends. Recently we've lost two or three of our friends, and now we can't find new friends anymore.I think it's because we're not going out. I work and don't socialize much, so I don't get much time to meet new people. (70-years old man)

(h): Coping with loneliness

One of the most important aspects emerged from the experiences of participants was the ways they used for coping: communicating with God, living with past memories and making new connections. The majority of older people in the study emphasized that believing in God gives them hope and the power to fight loneliness:

I always pray.I talk to God all day long.I ask God to give me strength, patience, mood, hope, and help me to get rid of this nostalgia and loneliness.All I hope is only for God. When I pray I feel better, power, and hope....If I have ever been able to endure, it is only because of trusting in God. (67 years old woman)

Two elderly men stated that their belief in God and being religious made them tolerate the current conditions of life and did not fall victim to Satan's temptations to commit suicide:

I'm tired of life. I do not know why God does not please me, make me comfortable. How many times has the devil tempted me to kill myself.But I just thought about it, I didn't do it because this is a great sin.Disappointment from God is a great $\sin$. (84 years old man)

Also, the majority of older people in this study described living with past memories as a way of coping with loneliness, which included recalling memories of different periods of life. Desire to live with memories of the past makes elderly move to a desirable past world, and feeling less loneliness. Seniors who lost their spouses, said that they often live with the memory of their spouses:

I remember my wife when I am alone, I remember when we were together, the kids were small, and we were all there, .... (65 years old man)

The experiences of a number of participants revealed that they cope with loneliness by creating new intimate and trusted relationships: 
I try to overcome my loneliness by findings new friends. Recently I have found a friend who also was alone. His wife died recently. He was very lonely. Ever since we get together and things got better, much better.Both for him and for me,we've been talking together talking from military service... we play chess, backgammon, and horoscope (the elderly says with gusto). I'll be less loneliness this way. (70 years old man)

)I) Feeling abandoned, worthlessness

The feeling of abandonment was described as the feeling of being neglected and unseen. They believed that since many of their close relatives died, they left alone by other members of family and the community. No one came to see them, no one called them and no one answered their phone.

You feel abandoned.... You have no place in community....You are no longer a part ... You are rejected. (70 years old woman)

This feeling of being a burden to their family was another reason for the feeling of worthlessness in the elderly:

You are old and depressed and you feel bothered. Yes it bothers me. When I here my children say we have to take care of our mother, oh, mother needs this, mother needs that . (70 years old woman)

Another participant said: that:

You feel as you are nobody, and there is nothing inside you that gives others a reason to know you (65 years old woman).

2-2 Consequences of loneliness derived from fieldwork

A number of consequences of loneliness were identified. These include: shame, embarrassment, feeling defeated, negative emotions, feeling nonsense, death, depression, anxiety, anger, despair, fear, lack of meaning, disrespect, rejection, lack of freedom and personal choice, feeling captive, physical complaints, mourn, regret, suicidal thoughts,

2-3 Features derived from the review of the literature and fieldwork

In this study, the features of loneliness in older adults are shown in Table 2.

\section{2-4 Practical definition}

The loneliness is an unpleasant, negative, annoying, hard, scary and painful personal experience that causes feeling of despair, uselessness, hopelessness, depression, anxiety and seeing the world in black.

\section{Discussion}


Because of the importance of loneliness in older adults, the concept analysis approach was used to clarify the concept of loneliness. Data analysis revealed a number of attributes for loneliness in older adults. A brief discussion on some of these attributes is presented as follows.

One of the themes extracted indicated that loneliness was 'personal, subjective and individual phenomena'. This is very similar to the notion of 'subjective phenomenon' in the theoretical phase. These findings support the belief that loneliness is a subjective phenomenon and also emphasize the importance of understanding the experience of loneliness [70]. In fact, loneliness is a private experience and could be differ from one person to another. Features and the intensity of loneliness could change depending on one's personality and past experiences in life. However, by better understanding the experience of loneliness and its complexities, more effective and long-lasting strategies can be developed to help older people address loneliness [71].

A review of the available evidence about loneliness in the elderly suggests that loneliness can lead to many psychological problems such as depression, fear, hopelessness, feeling unwell, sadness and anxiety $[20,23]$. Similarly, our participants referred to the suffering of negative and annoying emotions that damaged their psyche. It is noteworthy that all elderly had a very strong emphasis on shamelessness, which has not been addressed in other studies [17, 72]. The findings from Dahlberg's study showed that loneliness was perceived as wrong, ugly, and even embarrassing [73]. On the other hand, the findings of the current study showed that loneliness is not synonymous with living alone because elderly even living with their children or their spouse indicated that they were suffering from loneliness. Previous studies have also shown that being alone or living alone may have exacerbating effects on loneliness, but does not have the same meaning as loneliness. Anyone can live alone and never feel loneliness, on the contrary she or he may live with two or more people and suffer from loneliness [20].

Many seniors suffered from the loss of their beloved partner, friends and acquaintances of their peers. It was very important for them to have a caring family, but unfortunately some seniors saw that their family caring for them because they were obliged to do so, and caring was not out of sincere interest. Dalberg points out that a lack of belonging to important people in life plays an important role in feeling lonely [73]. It is believed that most seniors, who suffer from a lack of belonging to important people in life, live in an absurd situation. In this case, a sense of meaninglessness occur and people feel if they lost their vitality and motivation. The findings of our study are in line with the findings of Pinquart and Sorensen study where they have found that the quality of social contacts was more important than their quantity [74]. In their study, they found that communication with friends and neighbors had a stronger relationship with loneliness than relationship with family members. These findings underscore the importance of supporting the elderly in developing and maintaining social bonds with individuals of their own generation, and people with seniority who share similar experiences. Some studies emphasize that humans cannot live together without being together. Of course, being together without the concern is of little benefit to the elderly. This can be understood very well from their quotes when they complain that they are with others and live with others but do not receive any attention or care from them [75-77]. 
Loneliness could be felt at certain times. During some specific times seniors are more likely to feel loneliness than ever. Such understanding might help to provide help and support as appropriate and perhaps use preventive strategies more effectively. It is important to consider certain times of the year, during which seniors need support. Indeed focusing on primary health care and preventive strategies might be helpful [24].

Participants also emphasized that the lack of quality and quantity of support resources and barriers to access to services and facilities in the community worsened the situation. Some studies confirm the link between a lack of social support, support resources, and health care services with loneliness [78-80].

It should be noted that the restriction of access to adequate health care services, the geographical distance to health care centers, commuting problems, lack of social support and lack of awareness of existing services reduce the quality and quantity of elderly care and increase loneliness. In this study, the most potent forms of loneliness that older people talked about were disrespect, neglect, and abandonment.

Respect for and attention to elderly parents is strongly rooted in Iranian culture and religious beliefs [81]. Although the Iranian family is one of the finest families in receiving the elderly; specific social conditions such as urbanization, modernization, changing traditional values, the contradiction of the new and old generation value systems, and the unwillingness to accept care giving for elderly might contribute to feeling of loneliness among elderly population [82].

Findings related to the issue of factors that decrease feeling of loneliness might indicate that there are issues that loneliness involves a positive dimension that is experienced along with unpleasant feelings related to loneliness. Various studies have confirmed loneliness as a positive dimension and this concept suggests that working on this positive dimension can be helpful in serving the elderly[22].

Factors that contribute to loneliness have been linked to aging by itself [83]. Elderly people are at higher risk for experiencing loneliness for several reasons. Various age-related changes and failures may include: (a) the absence of a spouse/wife, partner or friend; (b) an increased symptoms of given diseases; (c) changes in financial status as a result of retirement; transportation and the possibility of relocation; and (e) dissatisfaction with changes in life plans. Age-related challenges hinder older people's mobility, limit their access to resources, and reduce their social networks [83].

Missing spouse/wife has been found to be one of the most common causes of loneliness among the elderly [84]. It has also been shown that mourning related to the affiliated people is associated with loneliness [85]. The most important factors associated with increasing loneliness are being widowed and lacking contact with children and friends. The prevalence and persistence of loneliness is greater among older people who live longer than their spouse, friends, or other family members [86].

Increased physical restraint has been shown to significantly increase loneliness in the elderly. Limiting social interactions due to poor health can lead to continued loneliness [87]. Friends were a significant 
source of support, especially for single and widowed seniors [88]. Late-life friends provide a way for each other to talk, and friendship plays a role in the experience of belonging. Friendships have a positive effect on the emotional well-being of the elderly. Emotional friendship seems to play a key role in reducing the likelihood of loneliness in the elderly. Sometime relationships with close friends are more important than relationships with family members in preventing loneliness [89].

This study supported the results of previous studies that emphasized the importance of coping mechanisms in loneliness [18-20, 25, 90]. Spiritual communication with God, living with past memories, and making new connections were among the strategies adopted by the elderly in this study. Participants emphasized that believing in God as a strong and supportive being and refuge would help them to relax, although some scholars believe that one's extra focus on spiritual issues by itself might lead to loneliness $[20,91]$. One study found that the majority of older people indicated that the relationship with God and religious activities was a means of inner peace for them [92]. Experts believe that belief in God and religious practices in old age play an important role in filling the empty space of life and overcoming loneliness [93]. Relationship with God and worship as a way of coping with loneliness has been reported by more than half of the elderly [19]. The majority of elderly people in this study described living with past memories as a choice to escape from loneliness. Reminding past memories can increase social interactions and adaptive performance and decrease loneliness in the elderly through increased selfesteem, self-worth, and life satisfaction [94]. Evidence suggests that active coping strategies can also be used to create new relationships when one is feeling emotionally alone [58].

This feeling in the elderly that their family or community no longer needed them was a serious threat to their self-esteem and contributed to lack of meaning and purpose in life. The seniors in their study felt they needed it, enjoyed life, enjoyed today's booty, yet looked to the future, and were aware of the limitations and possibilities of the future.

It meant connecting with the people present today and the past. If the amount of internal power is decreasing, a well-functioning social network can reduce the experience of loneliness and abandonment. In some studies, the feeling of abandonment is likened to homelessness [22] Homelessness has been described as: abandonment, loneliness, not being free, insecurity, homelessness and lack of meaningful activities.Homelessness can be described as a destructive force and a threat to the experience of being at home [95]. Feeling abandoned and unseen can be understood as a lack of confirmation that in turn could contribute to the feeling of homelessness [96]. Some studies emphasize that we become someone in relation to others. The authentication experience is closely linked to the personal experience and argues that identity is reinforced by the acknowledgment. Confirmation means: address me, you exist! We are related! Address me, you are important! Experience the world in the right way! So gaining approval and it can offset the effects of missing ones and prevent or reduce the experience of loneliness or abandonment [22].

\section{Conclusion}


The findings of this study provided an insight into the issue of loneliness as indicated by a concept analysis approach. Loneliness is a combination of positive and negative experiences that needs to be viewed by whom that experiences the phenomenon. The findings reveal important implications for the care of the elderly.

\section{Declarations}

\section{Acknowledgments}

We thank all participants who made this study possible.

\section{Ethics approval and consent to participate}

University of Social Welfare and Rehabilitation Sciences ethics committee approved the study. All participants signed informed consent form.

\section{Consent for publication}

Not applicable

\section{Availability of data and materials}

The datasets are available from the corresponding authors on request.

\section{Competing interests}

The authors declare that they have no competing interests.

\section{Funding}

None.

\section{Author's contributions}

FMSH and HKH was the study supervisor and contributed to all aspect of the study. RB was data collection, RB was the main investigator and provided the first draft. FMSH, HKH and AE were the study advisor and contributed to the study design, AM and RB critically reviewed the paper and provided the final draft. RB was the statistical advisor and contributed to data analysis. All authors read and approved of the final manuscript.

\section{References}

1. Mishra S. Does modern medicine increase life-expectancy: Quest for the Moon Rabbit? Indian heart journal. 2016;68(1):19-27. Epub 2016/01/18. doi: 10.1016/j.ihj.2016.01.003. 
2. Fujiwara E, Otsuka K Fau - Sakai A, Sakai A Fau - Hoshi K, Hoshi K Fau - Sekiai S, Sekiai S Fau Kamisaki M, Kamisaki M Fau - Ishikawa Y, et al. Usefulness of reminiscence therapy for community mental health. (1440-1819 (Electronic)).

3. Dziechciaz M, Filip R. Biological psychological and social determinants of old age: bio-psycho-social aspects of human aging. Ann Agric Environ Med. 2014;21(4):835-8. Epub 2014/12/23. doi: 10.5604/12321966.1129943.

4. Ong AD, Uchino BN, Wethington E. Loneliness and Health in Older Adults: A Mini-Review and Synthesis. Gerontology. 2016;62(4):443-9.

5. World Health Organization. World report on ageing and health. Retrieved from. https://www.who.int/ageing/publications/world-report-2015/en/. 2015

6. Fagerström J, Aartsen M. Successful ageing and its relationship to contemporary norms. A critical look at the call to "age well". Recherches sociologiques et anthropologiques. 2013;44(44-1):51-73.

7. Bandari R, Khankeh HR, Shahboulaghi FM, Ebadi A, Keshtkar AA, Montazeri A. Defining loneliness in older adults: protocol for a systematic review. Syst Rev. 2019;8(1):26. Epub 2019/01/19. doi: 10.1186/s13643-018-0935-y.

8. Yanguas J, Pinazo-Henandis S, Tarazona-Santabalbina FJ. The complexity of loneliness. Acta Biomed. 2018;89(2):302-14. Epub 2018/06/30. doi: 10.23750/abm.v89i2.7404.

9. Hudson NW, Roberts BW, Lodi-Smith J. Personality Trait Development and Social Investment in Work. Journal of research in personality. 2012;46(3):334-44. doi: 10.1016/j.jrp.2012.03.002.

10. Arslantaş H, Adana F, Abacigil Ergin F, Kayar D, Acar G. Loneliness in Elderly People, Associated Factors and Its Correlation with Quality of Life: A Field Study from Western Turkey. Iranian journal of public health. 2015;44(1):43-50.

11. Newall NEG, Menec VH. Loneliness and social isolation of older adults: Why it is important to examine these social aspects together. Journal of Social and Personal Relationships. 2019;36(3):925-39.

12. Rodgers BL, Knafl KA. Concept Development in Nursing: Foundations, Techniques, and Applications: Saunders; 2000.

13. Martha Raile Alligood PDRNA. Nursing Theorists and Their Work: Elsevier Health Sciences; 2013.

14. Schwartz-Barcott D, Kim H. An expansion and elaboration of the hybrid model of concept development. Concept Development in Nursing: Foundations, Techniques, and Applications. 2000;2:107-33.

15. Walker LO, Avant KC. Strategies for Theory Construction in Nursing. New Jersey: Pearson; 2010.

16. Roos V, Klopper H. Older persons' experiences of loneliness: a South African perspective. Journal of Psychology in Africa. 2010;20(2):281-9.

17. Hauge S, Kirkevold M. Variations in older persons' descriptions of the burden of loneliness. Scandinavian Journal of Caring Sciences. 2012;26(3):553-60. 
18. Roos $\mathrm{V}$, Malan L. The role of context and the interpersonal experience of loneliness among older people in a residential care facility. Global health action. 2012;5:10.3402/gha.v5i0.18861. doi: 10.3402/gha.v5i0.18861..

19. Mclnnis GJ, White JH. A phenomenological exploration of loneliness in the older adult. Arch Psychiatr Nurs. 2001;15(3):128-39. doi: 10.1053/apnu.2001.23751.

20. Heravi-Karimooi M, Anoosheh M, Foroughan M, Sheykhi MT, Hajizadeh E. Understanding loneliness in the lived experiences of Iranian elders. Scand J Caring Sci. 2010;24(2):274-80. Epub 2010/02/19. doi: 10.1111/j.1471-6712.2009.00717.x.

21. Smith JM. Toward a better understanding of loneliness in community-dwelling older adults. Journal of Psychology: Interdisciplinary and Applied. 2012;146(3):293-311.

22. Graneheim UH, Lundman B. Experiences of loneliness among the very old: the Umea 85+ project. Aging Ment Health. 2010;14(4):433-8. Epub 2010/05/11. doi: 10.1080/13607860903586078.

23. Heravi-Karimooi M, Rejeh N, Foroughan M, Vaismoradi M. Experience of loneliness in Iranian abused elders. International Nursing Review. 2012;59(1):139-45.

24. Stanley M, Moyle W, Ballantyne A, Jaworski K, Corlis M, Oxlade D, et al. 'Nowadays you don't even see your neighbours': Ioneliness in the everyday lives of older Australians. Health Soc Care Community. 2010;18(4):407-14. doi: 10.1111/j.1365-2524.2010.00923.x.

25. Taube E, Jakobsson U, Midlov P, Kristensson J. Being in a Bubble: the experience of loneliness among frail older people. J Adv Nurs. 2016;72(3):631-40. Epub 2015/11/17. doi: 10.1111/jan.12853.

26. Kvaal K, Halding AG, Kvigne K. Social provision and loneliness among older people suffering from chronic physical illness. A mixed-methods approach. Scandinavian journal of caring sciences. 2014;28(1):104-11.

27. Hauge S, Kirkevold M. Variations in older persons' descriptions of the burden of loneliness. Scand J Caring Sci. 2012;26(3):553-60. Epub 2012/01/12. doi: 10.1111/j.1471-6712.2011.00965.x

28. Theeke LA, Mallow J, Gianni C, Legg K, Glass C. The Experience of Older Women Living with Loneliness and Chronic Conditions in Appalachia. Rural Ment Health. 2015;39(2):61-72. Epub 2015/11/26. doi: 10.1037/rmh0000029

29. Rokach A, Orzeck T, Neto F. Coping with loneliness in old age: A cross-cultural comparison. Current Psychology. 2004;23(2):124.

30. O'Rourke HM, Collins L, Sidani S. Interventions to address social connectedness and loneliness for older adults: a scoping review. BMC Geriatr. 2018;18(1):214. Epub 2018/09/17. doi: 10.1186/s12877018-0897-x.

31. Stanley M, Richard A, Williams S. Older peoples' perspectives on time spent alone. Aust Occup Ther J. 2017;64(3):235-42. Epub 2016/12/15. doi: 10.1111/1440-1630.12353.

32. LaRocca MA, Scogin FR. The Effect of Social Support on Quality of Life in Older Adults Receiving Cognitive Behavioral Therapy. Clinical gerontologist. 2015;38(2):131-48. Epub 2015/01/13. doi: 10.1080/07317115.2014.990598. 
33. Haber MG, Cohen JL, Lucas T, Baltes BB. The relationship between self-reported received and perceived social support: A meta-analytic review. American journal of community psychology. 2007;39(1-2):133-44.

34. Low G, Molzahn AE, Kalfoss M. Quality of life of older adults in Canada and Norway: examining the lowa model. Western Journal of Nursing Research. 2008;30(4):458-76.

35. Cheung KC-K, Chou K-L. Poverty, deprivation and life satisfaction among Hong Kong older persons. Ageing \& Society. 2019;39(4):703-21.

36. Kvaal K, Halding AG, Kvigne K. Social provision and loneliness among older people suffering from chronic physical illness. A mixed-methods approach. Scandinavian journal of caring sciences. 2014;28(1):104-11.

37. Hawkley LC, Hughes ME, Waite LJ, Masi CM, Thisted RA, Cacioppo JT. From social structural factors to perceptions of relationship quality and loneliness: the Chicago health, aging, and social relations study. J Gerontol B Psychol Sci Soc Sci. 2008;63(6):S375-84.

38. Ong AD, Uchino BN, Wethington E. Loneliness and Health in Older Adults: A Mini-Review and Synthesis. Gerontology. 2016;62(4):443-9. Epub 2015/11/06. doi: 10.1159/000441651.

39. Uchino BN. Social support and health: a review of physiological processes potentially underlying links to disease outcomes. Journal of behavioral medicine. 2006;29(4):377-87.

40. Holt-Lunstad J, Smith TB, Baker M, Harris T, Stephenson D. Loneliness and social isolation as risk factors for mortality: a meta-analytic review. Perspectives on psychological science : a journal of the Association for Psychological Science. 2015;10(2):227-37.

41. Leigh-Hunt N, Bagguley D, Bash K, Turner V, Turnbull S, Valtorta N, et al. An overview of systematic reviews on the public health consequences of social isolation and loneliness. Public Health. 2017;152:157-71. doi: 10.1016/j.puhe.2017.07.035.

42. Beutel ME, Klein EM, Brähler E, Reiner I, Jünger $C$, Michal M, et al. Loneliness in the general population: Prevalence, determinants and relations to mental health. BMC Psychiatry. 2017;17(1). doi: 10.1186/s12888-017-1262-x.

43. Wang J, Mann F, Lloyd-Evans B, Ma R, Johnson S. Associations between loneliness and perceived social support and outcomes of mental health problems: a systematic review. BMC psychiatry. 2018;18(1):156.

44. Marketon JIW, Glaser R. Stress hormones and immune function. Cellular immunology. 2008;252(12):16-26.

45. Reed RG. Stress and immunological aging. Current opinion in behavioral sciences. 2019;28:38-43.

46. Momtaz YA, Hamid TA, Yusoff S, Ibrahim R, Chai ST, Yahaya N, et al. Loneliness as a risk factor for hypertension in later life. Journal of aging and health. 2012;24(4):696-710.

47. Petitte T, Mallow J, Barnes E, Petrone A, Barr T, Theeke L. A systematic review of loneliness and common chronic physical conditions in adults. The open psychology journal. 2015;8(Suppl 2):113. 
48. Valtorta NK, Kanaan M, Gilbody S, Ronzi S, Hanratty B. Loneliness and social isolation as risk factors for coronary heart disease and stroke: Systematic review and meta-analysis of longitudinal observational studies. Heart. 2016;102(13):1009-16.

49. Xia N, Li H. Loneliness, social isolation, and cardiovascular health. Antioxidants \& redox signaling. 2018;28(9):837-51.

50. Hakulinen C, Pulkki-Råback L, Virtanen $M$, Jokela $M$, Kivimäki $M$, Elovainio M. Social isolation and Ioneliness as risk factors for myocardial infarction, stroke and mortality: UK Biobank cohort study of 479054 men and women. Heart. 2018;104(18):1536-42.

51. Theeke L, Horstman P, Mallow J, Lucke-Wold N, Culp S, Domico J, et al. Quality of life and loneliness in stroke survivors living in Appalachia. The Journal of neuroscience nursing : journal of the American Association of Neuroscience Nurses. 2014;46(6):E3-E15.

52. Dyal SR, Valente TW. A systematic review of loneliness and smoking: small effects, big implications. Substance use \& misuse. 2015;50(13):1697-716.

53. Cacioppo S, Capitanio JP, Cacioppo JT. Toward a neurology of loneliness. Psychological bulletin. 2014;140(6):1464.

54. Sutin AR, Stephan Y, Luchetti M, Terracciano A. Loneliness and Risk of Dementia. J Gerontol B Psychol Sci Soc Sci. 2018. Epub 2018/10/27. doi: 10.1093/geronb/gby112.

55. Brown EG, Gallagher S, Creaven AM. Loneliness and acute stress reactivity: A systematic review of psychophysiological studies. Psychophysiology. 2018;55(5):e13031.

56. Wang G, Hu M, Xiao SY, Zhou L. Loneliness and depression among rural empty-nest elderly adults in Liuyang, China: a cross-sectional study. BMJ Open. 2017;7(10):e016091. Epub 2017/10/06. doi: 10.1136/bmjopen-2017-016091.

57. Zhao L, Zhang X, Ran G. Positive coping style as a mediator between older adults' self-esteem and loneliness. Social Behavior and Personality. 2017;45(10):1619-28. doi: 10.2224/sbp.6486.

58. Luanaigh CO, Lawlor BA. Loneliness and the health of older people. Int J Geriatr Psychiatry. 2008;23(12):1213-21. Epub 2008/06/10. doi: 10.1002/gps.2054.

59. O'Keeffe M, Kelly M, O'Herlihy E, O'Toole PW, Kearney PM, Timmons S, et al. Potentially modifiable determinants of malnutrition in older adults: A systematic review. Clin Nutr. 2018. Epub 2019/01/28. doi: 10.1016/j.clnu.2018.12.007.

60. Eskelinen K, Hartikainen S, Nykänen I. Is Loneliness Associated with Malnutrition in Older People? International Journal of Gerontology. 2016.

61. Aminzadeh F, Dalziel WB. Older adults in the emergency department: a systematic review of patterns of use, adverse outcomes, and effectiveness of interventions. Annals of emergency medicine. 2002;39(3):238-47.

62. Vingeliene S, Hiyoshi A, Lentjes M, Fall K, Montgomery S. Longitudinal analysis of loneliness and inflammation at older ages: English longitudinal study of ageing. Psychoneuroendocrinology. 2019;110:104421. 
63. Hajek A, König H-H. The association between obesity and social exclusion in middle-aged and older adults: findings from a nationally representative study in Germany. BMC geriatrics. 2018;18(1):258.

64. Ray J, Popli G, Fell G. Association of cognition and age-related hearing impairment in the English Longitudinal Study of Ageing. JAMA Otolaryngology-Head \& Neck Surgery. 2018;144(10):876-82.

65. Liebke L, Bungert M, Thome J, Hauschild S, Gescher DM, Schmahl C, et al. Loneliness, Social Networks, and Social Functioning in Borderline Personality Disorder. Personality Disorders: Theory, Research, and Treatment. 2017;8(4):349-56. doi: 10.1037/per0000208.

66. Sagan 0 . The loneliness of personality disorder: A phenomenological study. Mental Health and Social Inclusion. 2017;21(4):213-21. doi: 10.1108/MHSI-04-2017-0020.

67. Donovan NJ, Wu Q, Rentz DM, Sperling RA, Marshall GA, Glymour MM. Reciprocal relations of loneliness and cognitive function in older U.S. Adults. Alzheimer's and Dementia. 2015;11(7):P201P2.

68. Lara E, Caballero FF, Rico-Uribe LA, Olaya B, Haro JM, Ayuso-Mateos JL, et al. Are loneliness and social isolation associated with cognitive decline? International journal of geriatric psychiatry. 2019;34(11):1613-22.

69. El Haj M, Jardri R, Laroi F, Antoine P. Hallucinations, loneliness, and social isolation in Alzheimer's disease. Cogn Neuropsychiatry. 2016;21(1):1-13. Epub 2016/01/08. doi: 10.1080/13546805.2015.1121139.

70. Perlman D. European and Canadian studies of loneliness among seniors. Canadian Journal on Aging. 2004;23(2):181-8.

71. Sander R. Preventing social isolation and loneliness among older people: a systematic review of health promotion interventions. Nurs Older People. 2005;17(1):40. doi: 10.7748/nop.17.1.40.s11.

72. Theeke LA, Mallow JA. The development of listen: a novel intervention for loneliness. Open J Nurs. 2015;5(2):136-43. doi: 10.4236/ojn.2015.52016.

73. Dahlberg K. The enigmatic phenomenon of loneliness. International Journal of Qualitative Studies on Health and Well-being. 2007;2(4):195-207.

74. Pinquart M, Sorensen S. Influences on loneliness in older adults: A meta-analysis. Basic and applied social psychology. 2001;23(4):245-66.

75. Gerino E, Rollè L, Sechi C, Brustia P. Loneliness, resilience, mental health, and quality of life in old age: A structural equation model. Frontiers in Psychology. 2017;8(NOV). doi: 10.3389/fpsyg.2017.02003.

76. Higuchi M. Managing loneliness in the elderly and finding meaning in ageing. Journal of Comprehensive Nursing Research and Care. 2018;125.

77. Maharani A, Pendleton N, Leroi I. Hearing Impairment, Loneliness, Social Isolation, and Cognitive Function: Longitudinal Analysis Using English Longitudinal Study on Ageing. The American Journal of Geriatric Psychiatry. 2019;27(12):1348-56. 
78. Heu LC, van Zomeren M, Hansen N. Lonely alone or lonely together? A Cultural-psychological examination of individualism-Collectivism and loneliness in five European countries. Personality and Social Psychology Bulletin. 2019;45(5):780-93.

79. Burback D, Molnar FJ, John PS, Man-Son-Hing M. Key methodological features of randomized controlled trials of Alzheimer's disease therapy. Dementia and geriatric cognitive disorders. 1999;10(6):534-40.

80. Malcolm M, Frost $\mathrm{H}$, Cowie J. Loneliness and social isolation causal association with health-related lifestyle risk in older adults: a systematic review and meta-analysis protocol. Syst Rev. 2019;8(1):48. Epub 2019/02/09. doi: 10.1186/s13643-019-0968-x.

81. Yousif M. Journeying Through Islam, Society \& Culture: Understanding Divergent Interpretations of Marital Rape Within the Sudanese Patriarchy. 2019. doi: https://doi.org/10.7939/r3-wbx1-ka06.

82. Tajvar M, Arab M, Montazeri A. Determinants of health-related quality of life in elderly in Tehran, Iran. BMC public health. 2008;8(1):323.

83. Aebischer J. Loneliness among homebound older adults: implications for home healthcare clinicians. Home healthcare nurse. 2008;26(9):521-4.

84. Ron P. Depression, hopelessness, and suicidal ideation among the elderly: A comparison between men and women living in nursing homes and in the community. Journal of Gerontological Social Work. 2004;43(2-3):97-116.

85. Hawkley LC, Cacioppo JT. Loneliness matters: a theoretical and empirical review of consequences and mechanisms. Ann Behav Med. 2010;40(2):218-27. Epub 2010/07/24. doi: 10.1007/s12160-0109210-8.

86. Havens B, Hall M, Sylvestre G, Jivan T. Social isolation and loneliness: Differences between older rural and urban Manitobans. Canadian Journal on Aging. 2004;23(2):129-40.

87. Theeke LA. Predictors of Loneliness in U.S. Adults Over Age Sixty-Five. Archives of Psychiatric Nursing. 2009;23(5):387-96.

88. Eshbaugh EM. The role of friends in predicting loneliness among older women living alone. Journal of gerontological nursing. 2009;35(5):13-6.

89. Smith JM. Toward a better understanding of loneliness in community-dwelling older adults. Clinical and Translational Science. 2013;6(2):163.

90. Heravi-Karimooi M, Anoosheh M, Foroughan M, Sheykhi MT, Hajizadeh E. Designing and determining psychometric properties of the Domestic Elder Abuse Questionnaire. Iranian Journal of Ageing. 2010;5(7-12).

91. Kalliopuska M, Laitinen M. Loneliness related to self-concept. Psychological reports. 1991;69(1):2734.

92. Heravi Karimloo M, Anoosheh M, Foroughan M, Sheykhi MT, Hajizade E, Seyed Bagher Maddah MS, et al. Loneliness From the Perspectives of Elderly People: A Phenomenological Study. Yektaweb_Journals. 2008;2(4):410-20. 
93. Manning LK. Navigating hardships in old age: Exploring the relationship between spirituality and resilience in later life. Qualitative Health Research. 2013;23(4):568-75.

94. Bohlmeijer E, Roemer M, Cuijpers P, Smit F. The effects of reminiscence on psychological well-being in older adults: A meta-analysis. Aging and Mental Health. 2007;11(3):291-300.

95. Zingmark K. Experiences related to home in people with Alzheimer's disease [Doctoral thesis, comprehensive summary]. Umeå: Umeå universitet; 2000.

96. Sanders B, Brown B. I was all on my own': experiences of loneliness and isolation amongst homeless people. London: Crisis. http://www. crisis. org. uk/data/files/publications; 2015.

\section{Tables}

Table 1. Examples of the definition of loneliness in older adults in the theoretical phase

\begin{tabular}{|l|l|}
\hline Literature & definition of loneliness in older adults \\
\hline $\begin{array}{l}\text { Sullivan } \\
(1953)\end{array}$ & $\begin{array}{l}\text { Loneliness, is an incredibly unpleasant experience of inadequate } \\
\text { destruction requiring human intimacy }\end{array}$ \\
\hline Tillich (1959) & $\begin{array}{l}\text { The feeling of 'loneliness' expresses the pain of being alone and the } \\
\text { 'solitude' of expressing loneliness }\end{array}$ \\
\hline $\begin{array}{l}\text { Moustakas } \\
(1961)\end{array}$ & $\begin{array}{l}\text { Loneliness is an intrinsic and organic reality of human life in which there } \\
\text { is both pain and triumphant creation emerging out of long periods of } \\
\text { desolation }\end{array}$ \\
\hline Weiss (1974) & $\begin{array}{l}\text { Loneliness is caused not by being alone but by being without some definite } \\
\text { needed relationship or set of relations. In many instances it is a response } \\
\text { to the absence of provision of a close, indeed intimate, attachment. It also } \\
\text { may be a response to the absence of the provision of a meaningful } \\
\text { friendship, collegial relationship or other linkage to a coherent } \\
\text { community }\end{array}$ \\
\hline $\begin{array}{l}\text { Peplau and } \\
\text { Perlman: }\end{array}$ & $\begin{array}{l}\text { Loneliness is an unpleasant experience that occurs when a person's social } \\
\text { networking is impaired in an important dimension, whether qualitatively } \\
\text { or quantitatively }\end{array}$ \\
\hline $\begin{array}{l}\text { De Jong } \\
\text { Gierveld } \\
\text { (1987) }\end{array}$ & $\begin{array}{l}\text { Loneliness is what is experienced by the individual as a condition in which } \\
\text { there is an unpleasant or unacceptable (quality) of certain relationships. } \\
\text { This includes experiences in which the number of relationships available } \\
\text { is less than desired or accepted, as well as situations in which the } \\
\text { intimacy that the individual desires has not been achieved. It is thus } \\
\text { considered that loneliness involves a state in which one perceives, } \\
\text { experiences, and evaluates his or her own isolation or lack of } \\
\text { communication with others }\end{array}$ \\
\hline
\end{tabular}

Table 2: Features Derived from Review of the Literature and Fieldwork (Analytical Phase)

Personal 


\begin{tabular}{|l|l|l|}
\hline Theoretical phase & Fieldwork phase & $\begin{array}{l}\text { Analytical } \\
\text { phase }\end{array}$ \\
\hline Subjective phenomenon & $\begin{array}{l}\text { Personal, subjective and } \\
\text { individual phenomena }\end{array}$ & $\begin{array}{l}\text { Personal } \\
\text { feeling }\end{array}$ \\
\hline A wall of sorrow and pain loneliness & Sense of suffering & Suffering \\
\hline $\begin{array}{l}\text { Lack of meaningful interpersonal } \\
\text { relationships }\end{array}$ & $\begin{array}{l}\text { Breakdown of important } \\
\text { interpersonal relationships }\end{array}$ & Cohesion \\
\hline Loneliness as a time-related experience & $\begin{array}{l}\text { Experience of loneliness at } \\
\text { certain times }\end{array}$ & $\begin{array}{l}\text { Time } \\
\text { dependent }\end{array}$ \\
\hline Lack and deprivation & $\begin{array}{l}\text { Lack of quality and quantity of } \\
\text { support resources }\end{array}$ & Support \\
\hline Struggle for energy and resilience & Coping with loneliness & Coping \\
\hline $\begin{array}{l}\text { Feeling useless, isolated and unable to } \\
\text { keep up with the flow of life }\end{array}$ & $\begin{array}{l}\text { Feeling abandoned, } \\
\text { worthlessness }\end{array}$ & Worthlessness \\
\hline & $\begin{array}{l}\text { Factors that increase } \\
\text { loneliness }\end{array}$ & $\begin{array}{l}\text { Increasing } \\
\text { factors }\end{array}$ \\
\hline & $\begin{array}{l}\text { Factors that decrease } \\
\text { loneliness }\end{array}$ & $\begin{array}{l}\text { Decreasing } \\
\text { factors }\end{array}$ \\
\hline
\end{tabular}

